\title{
Experimental study on thermodynamic characteristics of EPS lightweight soil
}

\author{
LUO Ruidong ${ }^{1}$, Li Liang ${ }^{2}$, LIU Ganbin² ${ }^{2}$ LU Xing ${ }^{2}$, YE Junneng ${ }^{2}$ \\ ${ }^{1}$ Institution of geotechnical engineering, Ningbo University, Ningbo 315211, China \\ ${ }^{2}$ Ningbo Rail Transit Group Co., Ltd., Ningbo 315010, P.R. China
}

\begin{abstract}
The dynamic triaxial tests of EPS light soil were carried out under the conditions of different temperature, dynamic stress, EPS mixing ratio, cement content and age period, and the effect of temperature on the dynamic properties of EPS light soil is analyzed prominently. The results show that with the increase of temperature, the dynamic elastic modulus of EPS light soil increases and the soil appears the phenomenon of thermal hardening. With the increase of cement content, the thermal hardening effect of the sample decreases, and the effect of cement content is greater than that of EPS content.
\end{abstract}

\section{Introduction}

Lightweight materials are used to fill roadbed to reduce structural weight, control roadbed settlement, improve its overall stability and reduce diseases. The use of lightweight materials provides a new technical means for reducing roadbed load and additional stress of soft soil roadbed[1-3]. Foam lightweight soil has the advantages of "light weight, convenient construction, high strength, small construction surface" and so on. It has received wide attention in the widening subgrade filling project of high-grade road reconstruction and expansion in our country. At present, scholars have carried out a series of studies on the static and dynamic characteristics of expanded polystrene light mixed soil at room temperature [4-7]. The dynamic characteristics of EPS light soil considering temperature effect has not been reported, which is a long-term and new development direction in the field of geotechnical engineering, and has important theoretical significance and application value.

In this paper, the typical (2) 2 layer muddy clay in Ningbo was selected as the material of EPS light soil, and the dynamic triaxial tests were carried out under the conditions of different temperature, dynamic stress, EPS mixing ratio, cement content, age and so on. The effect of temperature on the dynamic characteristics of EPS light soil was studied.

\section{Test scheme}

The soil used in the test is the typical (2) 2 layer muddy clay in Ningbo, and the lightweight material adopts polystyrene particle EPS, curing agent and 32.5\# ordinary Portland cement. The basic physical and mechanical parameters of raw soil are shown in Table 1. The particle size of lightweight material EPS is $2 \sim 4 \mathrm{~mm}$, the pure density of particles is $23.7 \mathrm{~kg} / \mathrm{m}^{3}$, and the bulk density is $15.9 \mathrm{~kg} / \mathrm{m}^{3}$.

Table 1 Physical and mechanical parameters of soil

\begin{tabular}{ccccccc}
\hline $\begin{array}{c}\text { Natural } \\
\text { water } \\
\text { content } \\
\omega / \%\end{array}$ & $\begin{array}{c}\text { Liquid Plastic } \\
\text { limit }\end{array} \begin{array}{c}\omega_{\mathrm{L}} / \% \\
\text { limit }\end{array} \omega_{\mathrm{P}} / \%$ & $\begin{array}{c}\text { Heavy } \\
\text { weight }\end{array} / \mathrm{kN.m}^{-3}$ & $\begin{array}{c}\text { Void } \\
\text { ratio }\end{array}$ & $\begin{array}{c}\text { Cohesion } \\
c / \mathrm{kPa}\end{array}$ & $\begin{array}{c}\text { Internal } \\
\text { friction } \\
\text { angle } \\
\varphi /{ }^{\circ}\end{array}$ \\
\hline 53.6 & 35.8 & 21.4 & 17.6 & 1.16 & 4.37 & 3.84 \\
\hline
\end{tabular}

(1) Sample preparation

The sample is prepared according to the mix ratio designed before the test, i.e., the cement used in the test is mixed with the water under the water-cement ratio of 0.5 , the dry soil of the spare raw material is mixed with water with $60 \%$ water content for 5 minutes, the calculated EPS particles are poured into the three valves of the inner diameter $39.1 \mathrm{~mm}$ for three times, and the sample is prepared by vibrating, curing and completing the sample preparation.

The dynamic triaxial tests under different EPS blending ratio, cement content, temperature and age are carried out by using the temperature-controlled static and dynamic triaxial tester. The test plan is shown in Table 2. Table 2 Test plan

\begin{tabular}{|c|c|c|c|c|}
\hline \multicolumn{1}{|c|}{ Table 2 Test plan } \\
$\begin{array}{c}\text { Consolidation } \\
\text { confining pressure } \\
\sigma_{3} / \mathrm{kPa}\end{array}$ & $\begin{array}{c}\text { age period } \\
\text { /day }\end{array}$ & $\begin{array}{c}\mathrm{EPS} \\
V_{\mathrm{S}}\end{array}$ & $\begin{array}{c}\text { Cement } \\
a_{\mathrm{w}} / \mathrm{kg}^{-3} \mathrm{~m}^{-3}\end{array}$ & $\begin{array}{c}\text { temperature } \\
T /{ }^{\circ} \mathrm{C}\end{array}$ \\
\hline 50 & $7,14,28$ & 0,1 & 50,100 & $15,40,70$ \\
\hline
\end{tabular}

Note: (1) the sine wave is used in the test, and the vibration mode adopts unidirectional pure compressive vibration;(2) the test vibration frequency is $1 \mathrm{~Hz}$; (3)the EPS mixing ratio Vs is the ratio of the pure volume of EPS particles to the pure volume of dry raw soil; the cement content aw is the mass of cement contained in light soil per unit volume; the amount of water added to the sample is the sum of the test water content of the soil sample $(60 \%)$ and the water-cement ratio of 0.5 water-cement ratio.

* Corresponding author: liuganbin@nbu.edu.cn 


\section{Dynamic strength of EPS light soil}

According to the test plan in table 2, the dynamic triaxial tests of EPS light soil under different consolidation conditions such as EPS blending ratio, cement content, age and temperature are carried out to study the dynamic strength characteristics of EPS light soil under different conditions.

\subsection{Dynamic characteristics \& vibration times}

The dynamic triaxial tests under different EPS blending ratio, cement content, age and temperature are carried out to study the characteristics of EPS light soil under long-term dynamic load under different conditions, and the effects of different test conditions on cumulative plastic strain, dynamic elastic modulus and dynamic elastic strain are analyzed.

Fig. 1 and 2 shows the test results of dynamic characteristics of EPS light soil for different cement content $\left(50 \mathrm{~kg} / \mathrm{m}^{3}, 100 \mathrm{~kg} / \mathrm{m}^{3}\right)$ and temperature $\left(15^{\circ} \mathrm{C}\right.$, $40^{\circ} \mathrm{C}, 70{ }^{\circ} \mathrm{C}$ ) at 7 days of age.

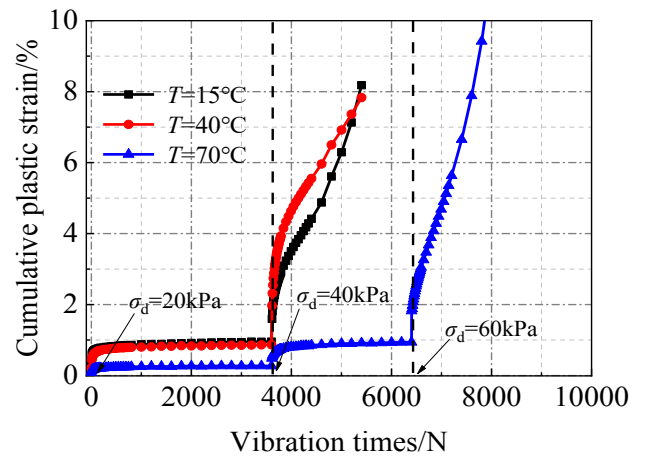

(a) $\mathrm{Vs}=1$, aw $=50 \mathrm{~kg} / \mathrm{m}^{3}$

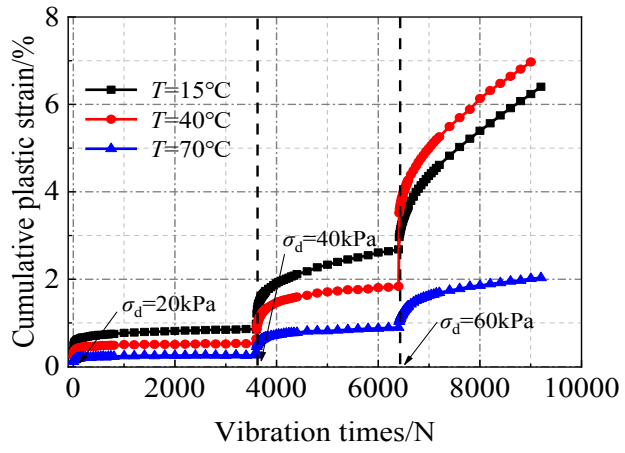

(b) $\mathrm{Vs}=1$, aw $=100 \mathrm{~kg} / \mathrm{m}^{3}$

Fig. 1 Effect of temperature on cumulative plastic strain

In Fig. 1 (a) and (b), the effect of temperature on cumulative plastic strain with the development of vibration times is given out. It can be seen that when the stress level is low (the specimen does not reach the failure mark), the cumulative plastic strain under different temperature conditions has the same development law with the vibration times, i.e., the cumulative plastic strain increases rapidly with the vibration times at the initial stage of vibration, and then gradually tends to be stable. In addition, when the mixing ratio of EPS, cement content and vibration times are the same, the higher the temperature is, the smaller the cumulative plastic strain is, and the greater the dynamic stress value is when the sample reaches failure (the cumulative plastic strain reaches $5 \%$ ).

The effect of temperature on dynamic elastic modulus with the development of vibration times is shown in Fig. 2(a) and (b). It can be seen from the figure that under the same age, EPS ratio and cement content, the higher the temperature is, the greater the initial dynamic elastic modulus $\mathrm{E}_{0}$ is and the larger the dynamic elastic modulu is under the condition of the same number of vibration times. The sample will gradually appear the phenomenon of thermal hardening with the increase of temperature. At low stress level, i.e., $\sigma_{\mathrm{d}}=20 \mathrm{kpa}$, the dynamic elastic modulus decreases rapidly at the initial stage of vibration, and then gradually recovers with the accumulation of vibration times. At the same temperature, this phenomenon will gradually disappear with the increase of the dynamic stress level. This is because the action of dynamic load, the cumulative plastic strain of the sample develops continuously, and the sample becomes densified, which leads to the recovery of the dynamic elastic modulus.

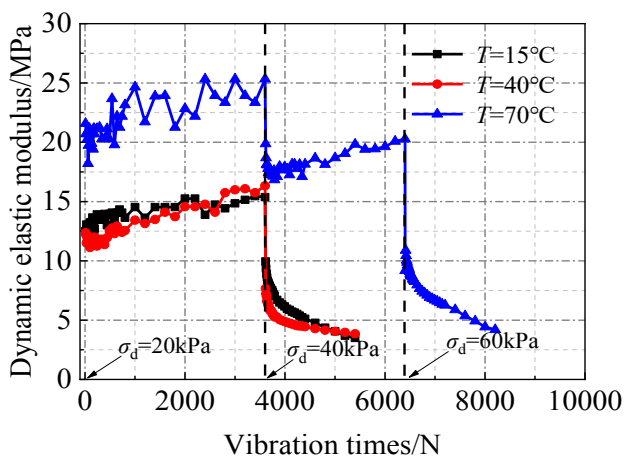

(a) $\mathrm{Vs}=1$, aw $=50 \mathrm{~kg} / \mathrm{m}^{3}$

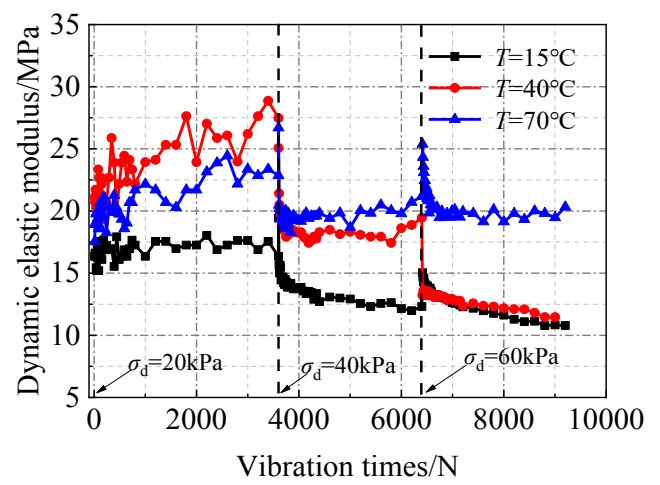

(b) $\mathrm{Vs}=1$, aw $=100 \mathrm{~kg} / \mathrm{m}^{3}$

Fig. 2 Effect of temperature on dynamic elastic modulus

\subsection{Dynamic stress-strain relationship}

The dynamic backbone curve under different temperatures is shown in Fig.3(a), (b) and (c) when the age period is 7 days, 14 days and 28 days, respectively.The mixing ratio of EPS is 0 and the cement content is $50 \mathrm{~kg} / \mathrm{m}^{3}$. It can be seen that at the same age, EPS blending ratio and cement content, the higher the temperature is, the greater the dynamic stress required to produce the same dynamic elastic strain is, and the thermal hardening phenomenon appears. With the development of age, the thermal hardening phenomenon 
weakens. In the figure (d), (e) and (f), the same phenomenon occurs when the mixing ratio of EPS is 1 and that of cement is $50 \mathrm{~kg} / \mathrm{m}^{3}$.

Comparing figure (b) and (g) in Fig. 3, It can be seen that the thermal hardening phenomenon of the sample decreases with the increase of cement content under the condition of the same age (14 days) and EPS blending ratio 0 , and the same phenomenon is also found in figure (e) and (h).

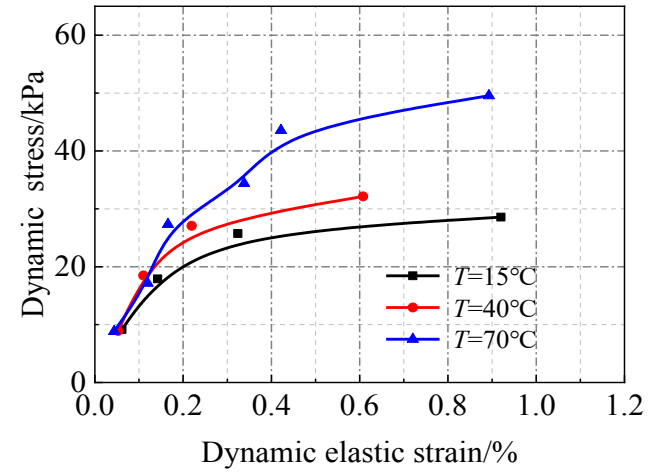

(a) $7 \mathrm{~d}, \mathrm{Vs}_{\mathrm{s}}=0$, aw $=50 \mathrm{~kg} / \mathrm{m}^{3}$

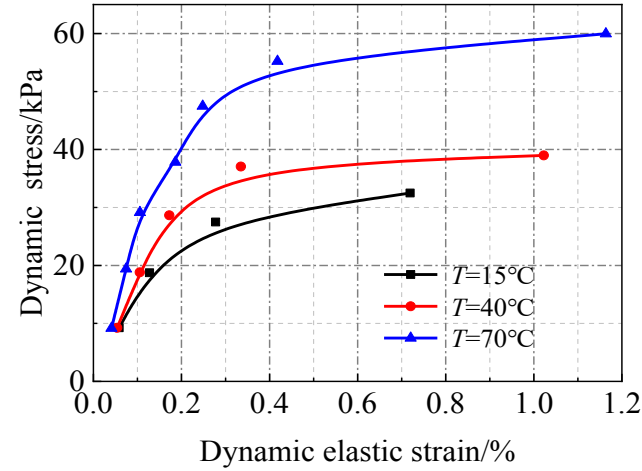

(b) $14 \mathrm{~d}, \mathrm{Vs}=0$, aw $=50 \mathrm{~kg} / \mathrm{m}^{3}$

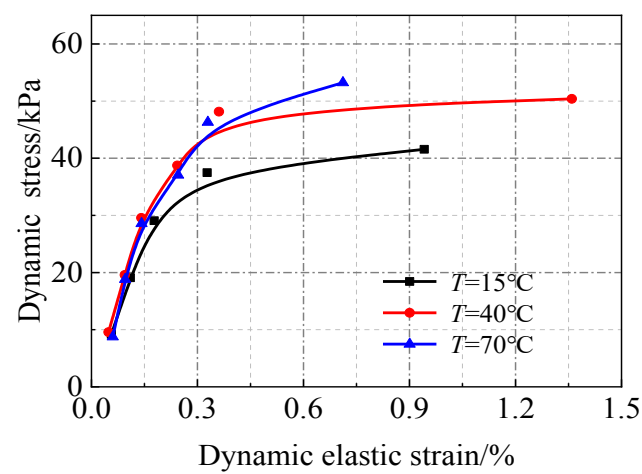

(c) $28 \mathrm{~d}, \mathrm{Vs}=0, \mathrm{aw}=50 \mathrm{~kg} / \mathrm{m}^{3}$

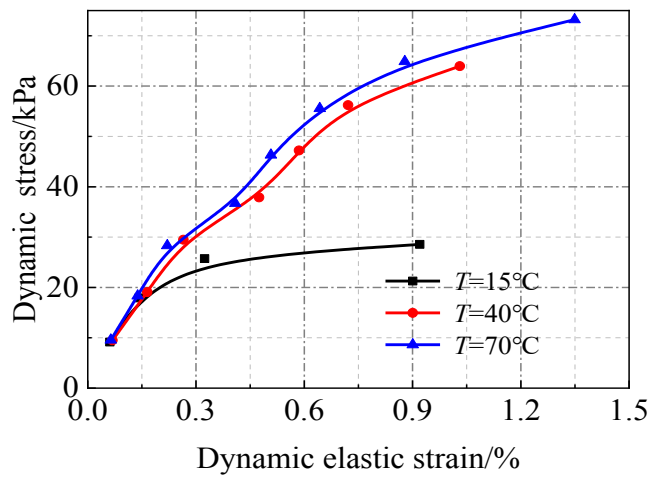

(d) $7 \mathrm{~d}, \mathrm{Vs}_{\mathrm{s}}=1$, aw $=50 \mathrm{~kg} / \mathrm{m}^{3}$

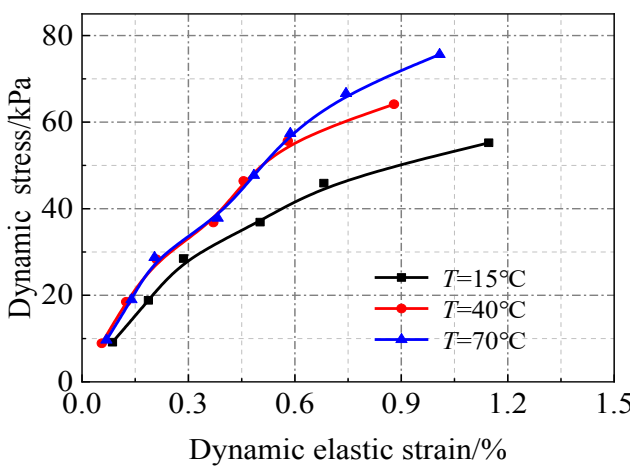

(e) $14 \mathrm{~d} 、 \mathrm{Vs}=1 、$ aw $=50 \mathrm{~kg} / \mathrm{m}^{3}$

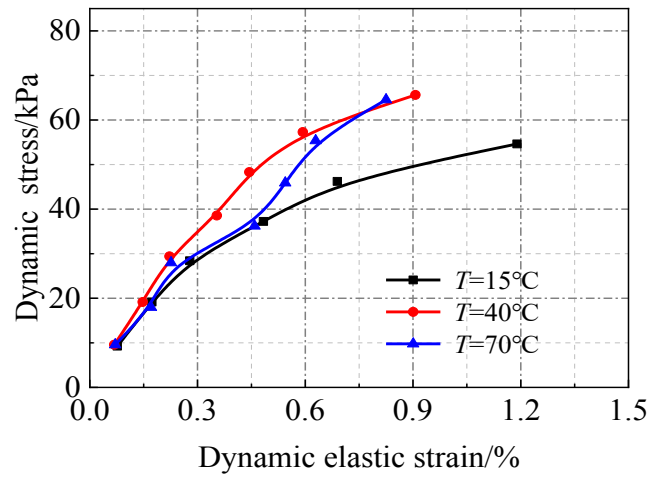

(f) $28 \mathrm{~d}, \mathrm{Vs}=1, \mathrm{aw}=50 \mathrm{~kg} / \mathrm{m}^{3}$

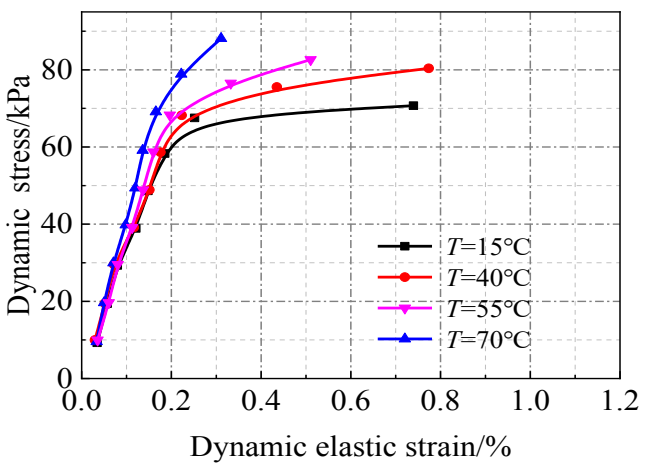

(g) $14 \mathrm{~d}, \mathrm{Vs}=0, \mathrm{aw}=100 \mathrm{~kg} / \mathrm{m}^{3}$

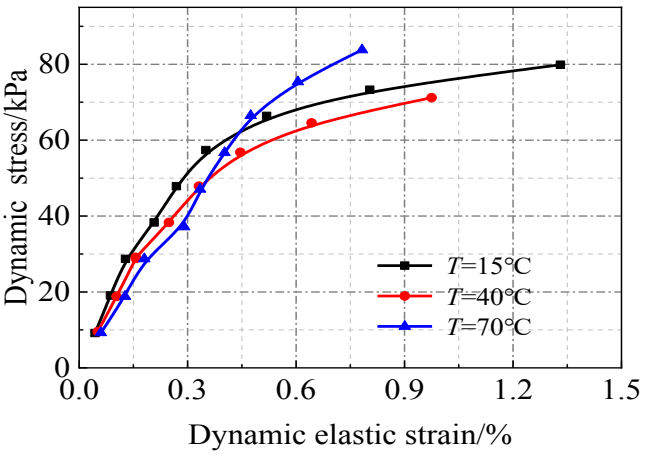

(h) $14 \mathrm{~d}, \mathrm{Vs}=1$, aw $=100 \mathrm{~kg} / \mathrm{m}^{3}$

Fig.3 Effect of temperature on dynamic stress $\sim$ strain

\subsection{Effect of temperature on dynamic elastic modulus}

The dynamic elastic modulus-dynamic elastic strain curves at different temperatures are obtained when the mixing ratio of EPS is 0 and the cement content is $50 \mathrm{~kg} / \mathrm{m}^{3}$ and shown in Fig.4(a), (b) and (c) for 7 days, 14 
days and 28 days respectively. It can be seen that at the same age, EPS blending ratio and cement content, the higher the temperature is, the greater the dynamic elastic modulus of the sample is.

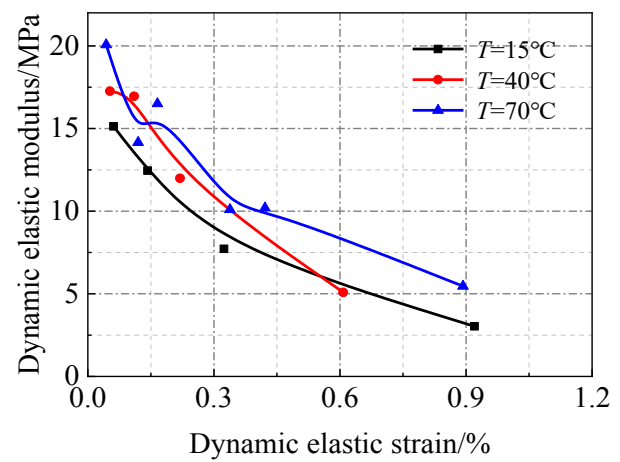

(a) $V_{s}=0$, aw $=50 \mathrm{~kg} / \mathrm{m}^{3}, 7 \mathrm{~d}$

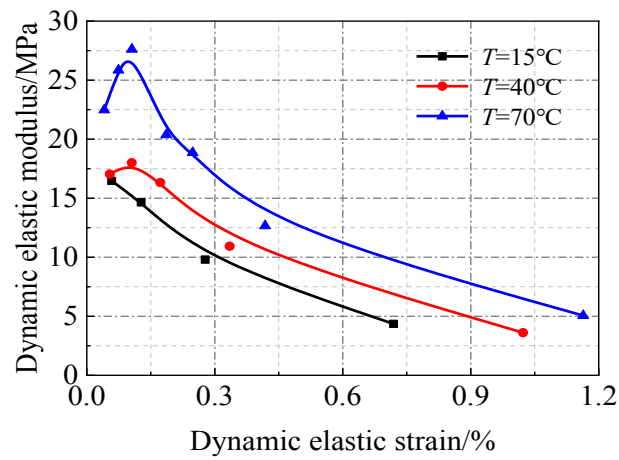

(b) $\mathrm{Vs}=0$, aw $=50 \mathrm{~kg} / \mathrm{m}^{3}, 14 \mathrm{~d}$

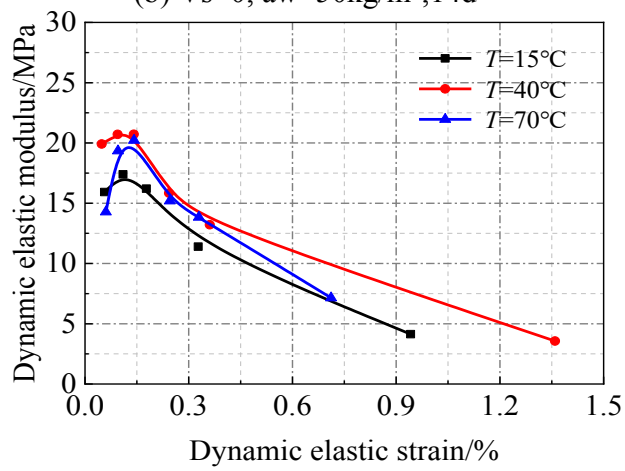

(c) $V_{s}=0, a w=50 \mathrm{~kg} / \mathrm{m}^{3}, 28 \mathrm{~d}$

Fig. 4 Effect of temperature on Ed-ed curves

There occurs thermal hardening phenomenon in EPS light soil, which can be explained in two aspects: first, the cement is added to EPS light soil and conventional cement soil as curing agent, and the curing product composed of cement-water-raw material soil has structure and a certain amount of airtight pores. When the amount of cement is small, the sample is only subjected to the confining pressure of $50 \mathrm{kPa}$ at constant temperature, the cured product has a certain compressive strength (low strength), and the skeleton can bear part of the pressure, and the amount of pore water is less due to the existence of closed pores. Under the condition of heating, the pore water in the closed space is destroyed by thermal expansion, and when the pore water is discharged, the strength of the sample increases, the dynamic elastic modulus increases, and thermal hardening occurs. With the increase of cement content, the structure of the cured product is strengthened, the more difficult it is to discharge pore water in the confined space, and the thermal hardening effect of the sample is weakened. Second, during the test, the heating procedure of the temperature control device is set to $10^{\circ} \mathrm{C} / 3 \mathrm{~h}$ in order to achieve the corresponding test temperature and ensure the uniformity of the sample temperature, so it takes at least 12 hours to reach the highest temperature. At the same time, each sample is heated and consolidated in the triaxial apparatus for 12 hours. Therefore, the sample is equivalent to the high temperature curing at the test temperature, and its strength is improved.

\section{Conclusion}

(1) Within a certain range of EPS mixing ratio $\left(V_{\mathrm{s}}=0,1\right)$ and cement content $\left(a_{\mathrm{w}}=50 \mathrm{~kg} / \mathrm{m}^{3}, 100 \mathrm{~kg} / \mathrm{m}^{3}\right)$, the effect of cement content on the dynamic characteristics of EPS light soil is more obvious than that of EPS mixing ratio.

(2) Thermal hardening occurs in EPS lightweight soil under the action of temperature. With the increase of temperature, the greater the dynamic stress required for EPS lightweight soil to produce the same dynamic elastic strain, the greater the dynamic elastic modulus.

(3) At low stress level, the dynamic elastic modulus decreases rapidly at the initial stage of vibration, and then gradually recovers with the accumulation of vibration times, even exceeding the initial dynamic elastic modulus value.

\section{Acknowledgement}

This research was supported by the Ningbo Science and Technology Plan Project (No. 2017C510002) and National Natural Science Foundation of China (No: 51778303) to which the author is grateful.

\section{References}

1. Minegishi K, Makiuchi K, Takahashi R. Proceeding of the international workshop on lightweight geomaterials. 2002.

2. Liu H.L., Dong J.M.,Zhou Y.D., etal., Chinese Rock mech., 26,3(2005)

3. Wang S.M., Gao Y.F., Chinese Rock mech., 28,5(2007)

4. Li J., Miu L.C., Zhong J.C.,et al. Chinese Rock mech., 31,6(2010)

5. Trandafir A.C., Erickson B. A., J. Mate. Civil Eng., 24,1(2012)

6. Gao H.M., Chen R., Tong F., Chen G.X., Cai X., Chinese J. Disaster Prevent. Mitig. Eng., 35,2(2015)

7. Gao H.M., Shen Y.Q., Wang Z.H., Chen G.X., Chinese J. Geo., Eng., 39, 2(2017) 